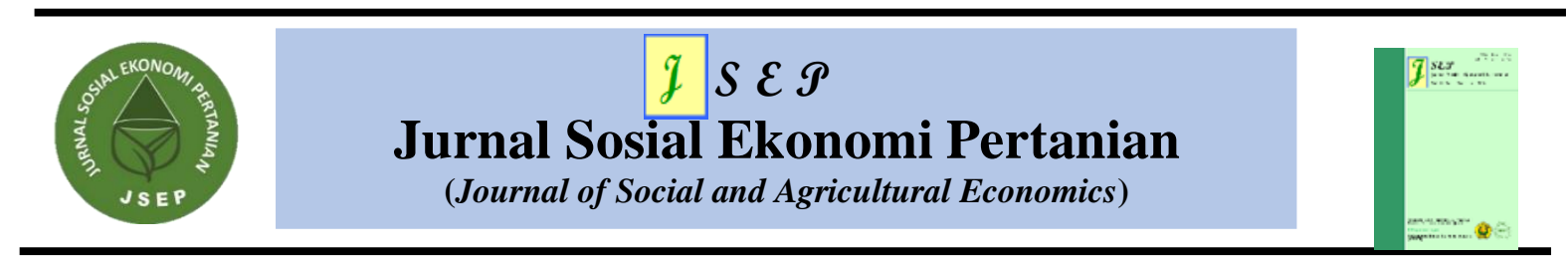

\title{
EFISIENSI PENGGUNAAN FAKTOR PRODUKSI DAN PENDAPATAN USAHATANI TUMPANGSARI STROBERI-BAWANG DAUN DI DESA SERANG KECAMATAN KARANGREJA KABUPATEN PURBALINGGA
}

\section{THE EFFICIENCY OF PRODUCTION FACTORS AND FARMER INCOME OF INTERCROPPING FARMING OF STRAWBERRY-LEEK IN SERANG VILLAGE KARANGREJA DISTRICT PURBALINGGA REGENCY}

\author{
Savira Kusumadewi ${ }^{1 *}$, Djeimy Kusnaman ${ }^{1}$ \& Irene Kartika Eka Wijayanti $^{1}$ \\ ${ }^{1}$ Progam Studi Agribisnis, Fakultas Pertanian, Universitas Jenderal Soedirman \\ *email : kusumasavira.25@gmail.com; telp:085860369839
}

\begin{abstract}
Strawberry (Fragaria sp.) is a type of fruit that has high economic value. An to increase the income of strawberry farmers is by intercropping with leek. To understand the efficiency of the farming the by using production input. This research aims to 1) analyze the effect of the use of production factors, 2) analyze the level of efficiency in the use of production factors, and 3) to analyze the profit level of intercropping strawberries-leek in Serang Village, Karangreja District, Purbalingga Regency. There are 35 samples obtained using simple random sampling. The analysis was performed using the Cobb Douglass production function analysis, the NPM / BKM ratio and farm income analysis. The results of this research were the use of production factors, seed; area; labor; and insecticides partially affected the production of intercropping strawberries, while the production factors of chicken-husk fertilizer; NPKPhonska fertilizer; other fertilizers; and fungicides had no effect on the production of intercropping strawberries. The production factors for seeds; labor; and insecticides have an NPM-BKM ratio value greater than one where the use of these inputs is not efficient. Meanwhile, the production factor for land area has an NPM-BKM ratio value of less than one where the use of these inputs is not efficient. $R / C$ for cash costs was 4.61 and $R / C$ for total costs was 1.09. The $R / C$ value for both cash costs and total costs has a value greater than one, so the strawberry and leek intercropping farming in Serang Village can be said to be profitable.
\end{abstract}

Keywords: intercropping strawberry-leek, cobb douglas, price efficiency, income

\begin{abstract}
ABSTRAK
Stroberi (Fragaria sp.) merupakan buah dengan nilai ekonomis tinggi. Upaya untuk meningkatkan pendapatan petani stroberi yakni dengan menggunakan faktor produksi secara efisien. Penelitian ini bertujuan untuk mengetahui : 1) Pengaruh penggunaan faktor produksi terhadap produksi stroberi, 2) Tingkat efisiensi harga penggunaan faktor produksi, dan 3) Tingkat pendapatan usahatani tumpangsari stroberi di Desa Serang. Terdapat 35 sampel didapat dengan menggunakan metode simple random sampling. Analisis data menggunakan fungsi produksi Cobb-Douglass, rasio NPM/BKM dan kelayakan usahatani. Hasil dari penelitian ini yaitu penggunaan faktor produksi bibit, luas lahan, tenaga kerja, dan insektisida secara parsial berpengaruh terhadap produksi tumpangsari stroberi, sedangkan faktor produksi pupuk ayam-sekam, pupuk NPK-Phonska, pupuk lainnya dan fungisida tidak berpengaruh terhadap produksi tumpangsari stroberi. Faktor produksi bibit, tenaga kerja, dan insektisida mempunyai nilai rasio NPM- BKM lebih besar dari satu di mana penggunaan input tersebut belum efisien. Faktor produksi luas lahan memiliki nilai rasio NPM-BKM kurang dari satu di mana penggunaan input tersebut sudah tidak efisien. R/C atas biaya tunai adalah sebesar 4,61 dan R/C atas biaya total adalah 1,09. Nilai R/C baik atas biaya tunai maupun biaya total memiliki nilai lebih besar daripada satu, sehingga usahatani tumpangsari stroberi dan bawang daun di Desa Serang dapat dikatakan menguntungkan.
\end{abstract}

Kata Kunci : usahatani tumpangsari stroberi-bawang daun, cobb-douglas, efisiensi harga, pendapatan How to Cite: Kusumadewi, S., Kusnaman, D., \& Wijayanti, I. K. E. (2021). Efisiensi Penggunaan Faktor Produksi Dan Pendapatan Usahatani Tumpangsari Stroberi-Bawang Daun di Desa Serang Kecamatan Karangreja Kabupaten Purbalingga. JSEP: Jurnal Sosial Ekonomi Pertanian, 14(1): 57-66. 


\section{PENDAHULUAN}

Stroberi tetap diusahakan di Desa Serang mengingat masih adanya permintaan yang harus dipenuhi. Oleh karenanya usahatani stroberi wajib untuk dioptimalkan. Kombinasi faktor produksi yang digunakan, menentukan produk pertanian yang dihasilkan. Penggunaan faktor-faktor produksi memegang peranan yang sangat penting guna memperoleh hasil produksi dan keuntungan yang maksimal. Jika terjadi kesalahan dalam penggunaan dan pengkombinasian faktor produksi mengakibatkan rendahnya produksi yang dihasilkan atau mempertinggi biaya produksi. Faktor produksi yang digunakan dalam usahatani stroberi di Kecamatan Karangreja adalah bibit, luas lahan, tenaga kerja, pupuk ayam-sekam, pupuk NPK-Phonska, pupuk lainnya, insektisida, dan fungisida. Pemilihan faktor produksi tersebut berdasarkan sifatnya yang dapat dikontrol oleh petani. Petani dapat mengetahui berapa jumlah faktor produksi atau masukan yang dipakai dalam usahataninya sehingga petani dapat menduga berapa produksi yang dihasilkan.

Usahatani stroberi di Kecamatan Karangreja ditanam secara tumpangsari. Menurut (Suwandi, Rosliani and Setiawati, 2003) beberapa keuntungan tumpangsari antara lain mengurangi risiko kerugian yang disebabkan fluktuasi harga pertanian, menekan biaya operasional seperti tenaga kerja dan pemeliharaan tanaman, dan meningkatkan produktivitas tanah sekaligus memperbaiki sifat tanah. Tanaman yang biasa ditumpang sarikan dengan stroberi di Kecamatan Karangreja ialah bawang daun. Petani dalam usahataninya tidak hanya berkepentingan untuk meningkatkan produksi saja, tetapi juga untuk meningkatkan pendapatannya. Pendapatan yang maksimal dapat diperoleh dengan cara menekan biaya produksi, memperbesar penerimaan, atau kombinasi keduanya. Kecenderungan produksi stroberi di Kecamatan Karangreja yang menurun dalam lima tahun terakhir berpengaruh kepada pendapatan petani. Upaya yang dapat dilakukan untuk meningkatkan pendapatan petani stroberi di Kecamatan Karangreja yakni dengan menggunakan faktor produksi secara efisien.

Penelitian ini berbeda dari penelitian-penelitian sebelumnya di mana dalam penelitian ini mengkaji analisis efisiensi ekonomi penggunaan faktor produksi pada usahatani tumpangsari stroberi dan bawang daun. Penelitian ini dilakukan pada tahun 2020 dengan populasi petani tumpangsari stroberi dengan bawang daun yang bertempat di Desa Serang, Kecamatan Karangreja, Kabupaten Purbalingga. Tujuan penelitian ini yaitu untuk mengetahui: 1) pengaruh penggunaan faktor produksi bibit, luas lahan, tenaga kerja, pupuk ayam-sekam, pupuk NPK-Phonska, pupuk lain, insektisida, dan fungisida yang digunakan dalam usahatani tumpangsari stroberi dengan bawang daun; 2) Tingkat efisiensi harga penggunaan faktor produksi bibit, luas lahan, tenaga kerja, pupuk ayam-sekam, pupuk NPK-Phonska, pupuk lain, insektisida, dan fungisida yang digunakan dalam usahatani tumpangsari stroberi dengan bawang daun; 3) Tingkat pendapatan usahatani tumpangsari stroberi dengan bawang daun.

\section{METODE PENELITIAN}

Metode yang digunakan dalam penelitian ini ialah survey. Penelitian dilaksanakan di Desa Serang, Kecamatan Karangreja, Kabupaten Purbalingga, Jawa Tengah pada bulan Juli-Agustus 2020. Subjek penelitian ini adalah petani di Desa Serang, Kecamatan Karangreja, Kabupaten Purbalingga yang melakukan usahatani tumpangsari stroberi dengan bawang daun pada musim tanam 2019. Metode penentuan sampel petani dengan cara simple random sampling, yakni suatu metode penentuan sampel penelitian yang dilakukan secara acak dan tidak mempertimbangkan strata atau 
tingkatan dalam populasi (Sugiyono, 2001). Berdasarkan perhitungan simple random sampling jumlah sampel petani responden sebesar 35 orang. Untuk mencapai tujuan pertama, menggunakan variabel produksi stroberi-bawang daun $(\mathrm{Y})$, bibit $\left(\mathrm{X}_{1}\right)$, luas lahan $\left(\mathrm{X}_{2}\right)$, tenaga kerja $\left(\mathrm{X}_{3}\right)$, pupuk ayam-sekam $\left(\mathrm{X}_{4}\right)$, pupuk NPK-Phonska $\left(\mathrm{X}_{5}\right)$, pupuk lainnya $\left(\mathrm{X}_{6}\right)$, insektisida $\left(\mathrm{X}_{7}\right)$, dan fungisida $\left(\mathrm{X}_{8}\right)$.

Analisis data yang digunakan dalam penelitian ini ialah :

1. Analisis Fungsi Produksi Cobb-Douglass

Model ini digunakan untuk mengetahui faktor- faktor yang mempengaruhi tingkat produksi usahatani stroberi dengan menggunakan fungsi produksi CobbDouglas. Fungsi produksi Cobb-Douglas ditulis sebagai berikut :

Keterangan:

$$
\mathrm{Y}=a \mathrm{X}_{1}^{b 1} \mathrm{X}_{2}^{b 2} \mathrm{X}_{3}{ }^{b 3} \mathrm{X}_{4}{ }^{b 4} \mathrm{X}_{5}^{b 5} \mathrm{X}_{6}^{b 6} \mathrm{X}_{7}^{b 7} \mathrm{X}_{8}{ }^{b 8} e^{u}
$$

$\mathrm{Y} \quad=$ Produksi stroberi-bawang daun $(\mathrm{kg})$

a $\quad=$ Konstanta

$b_{i} \quad=$ Koefisien regresi, di mana $i=1,2 \ldots .8$

$\mathrm{X} 1=$ Bibit (pohon)

$\mathrm{X} 2=$ Luas lahan $(\mathrm{m} 2)$

$\mathrm{X} 3=$ Tenaga kerja (HKSP)

X4 = Pupuk Ayam-Sekam (kg)

X5 = Pupuk NPK-Phonska $(\mathrm{kg})$

$\mathrm{X} 6=$ Pupuk lainnya $(\mathrm{Rp})$

$\mathrm{X} 7 \quad=$ Insektisida $(\mathrm{Rp})$

$\mathrm{X} 8=$ Fungisida $(\mathrm{Rp})$

e $\quad=$ Logaritma Natural, e $=2,718$

$\mathrm{u} \quad=$ Kesalahan (disturbance term)

2. Efisiensi Harga

Efisiensi harga terjadi jika penggunaan faktor produksi optimum atau keuntungannya mencapai maksimum, yaitu pada saat nilai produk marjinal (NMPXi) sama dengan harga inputnya (PXi) atau Biaya Korbanan Marjinal (BKMXi) :

$$
\begin{gathered}
\pi=\mathrm{P}_{\mathrm{Y}} \cdot \mathrm{f}(\mathrm{X})-\mathrm{P}_{\mathrm{X}} \cdot \mathrm{X}-\mathrm{TFC} \\
\mathrm{d} \pi / \mathrm{dx}=\mathrm{P}_{\mathrm{Y}} \cdot \mathrm{dY} / \mathrm{dx}-\mathrm{Px}=0 \\
\mathrm{~d} \pi / \mathrm{dx}=\mathrm{P}_{\mathrm{Y}} \cdot \mathrm{PM}-\mathrm{Px}=0 \\
\text { atau } \\
\mathrm{P}_{\mathrm{Y}} \cdot \mathrm{PM}=\mathrm{P}_{\mathrm{X}} \\
\mathrm{NPM}_{\mathrm{X}}=\mathrm{P}_{\mathrm{X}} \\
\mathrm{NPM}_{\mathrm{X}} / \mathrm{P}_{\mathrm{X}}=1
\end{gathered}
$$

Penggunaan untuk faktor produksi lebih dari satu misalnya $\mathrm{n}$ faktor produksi, maka efisiensi ekonomi dapat dicapai jika:

NPMx $1 /$ BKMx $1=$ NPMx2 $/$ BKMx2 = NPMx3 $/$ BKMx3 ... NPMxi $/$ BKMxi $=1$

NPMxi = Pxi; atau NPMxi = BKMxi

Keterangan :

NPMXi = Nilai produk marjinal faktor produksi Xi (satuan)

$\mathrm{Xi} \quad=$ Jumlah faktor produksi $\mathrm{Xi}$

$\mathrm{Y} \quad=$ Produksi

$\mathrm{Px}_{\mathrm{i}} \quad=$ Harga faktor produksi ke-i

$\mathrm{BKMxi} \quad=$ Biaya Korbanan Marginal Xi 
Kriteria pengujiannya :

$\frac{\mathrm{NPMxi}}{\mathrm{BKMxi}}=1$, maka penggunaan faktor produksi ke-i pada tingkat harga yang berlaku sudah optimum atau secara ekonomi sudah efisien.

$\frac{\mathrm{NPMxi}}{\mathrm{BKMxi}}>1$, maka penggunaan faktor produksi ke-i pada tingkat harga yang berlaku, belum berada pada tingkat optimum atau secara ekonomi tidak efisien

$\frac{\mathrm{NPMxi}}{\mathrm{BKMxi}}<1$, maka penggunaan faktor produksi ke-i pada tingkat harga yang berlaku, sudah terlampaui atau secara ekonomi tidak efisien lagi (Soekartawi, 2003)

\section{Analisis Pendapatan}

Analisis pendapatan petani tumpangsari stroberi dilakukan dengan mencatat seluruh penerimaan dan pengeluaran usahatani tersebut dalam satu musim produksi. Pendapatan petani dapat dirumuskan sebagai berikut:

$$
\begin{aligned}
& \pi \text { Tunai }=\left(\mathrm{TR}_{1}+\mathrm{TR}_{2}\right)-\mathrm{TC} \\
& \mathrm{TR}_{1}=\mathrm{Py}_{\text {stroberi }} x \mathrm{Y}_{\text {stroberi }} \\
& \mathrm{TR}_{2}=\text { Pybawang daun } x \mathrm{Y}_{\text {bawang daun }} \\
& \mathrm{TC}=\sum \mathrm{Px}_{\text {input tumpangsari }} x \mathrm{X}_{\text {input tumpangsari }} \\
& \pi \text { Tot }=\mathrm{TR}_{\text {total }}-(\mathrm{TC}+\mathrm{CC})
\end{aligned}
$$

Keterangan:

$$
\begin{array}{ll}
\pi & =\text { Pendapatan }(\mathrm{Rp}) \\
\text { TR1 } & =\text { Penerimaan stroberi }(\mathrm{Rp}) \\
\text { TR2 } & =\text { Penerimaan bawang daun }(\mathrm{Rp}) \\
\text { TRtotal } & =\text { Total penerimaan }(\mathrm{Rp}) \\
\text { TC } & =\text { Biaya tunai produksi }(\mathrm{Rp}) \\
\mathrm{CC} & =\text { Biaya yang diperhitungkan }(\mathrm{Rp}) \\
\mathrm{Py} & =\text { Harga jual }(\mathrm{Rp}) \\
\mathrm{Px} & =\text { Harga beli input }(\mathrm{Rp}) \\
\mathrm{Y} & =\text { Jumlah output total }(\mathrm{kg}) \\
\mathrm{X} & =\text { Jumlah input produksi (satuan) }
\end{array}
$$

Besar kecilnya pendapatan dari suatu usahatani dinilai dengan analisis Cost Ratio (R/C Ratio). Imbangan penerimaan dan biaya (R/C) rasio merupakan perbandingan anatar total penerimaan dengan total biaya yang dikeluarkan dalam usahatani. Analisis ini dilakukan atas biaya tunai dan biaya total yang dirumuskan sebagai berikut:

Kriteria pengujiannya :

$$
\begin{aligned}
& \mathrm{R} / \mathrm{C} \text { atas biaya tunai }=\frac{\text { Total Penerimaan }}{\text { Total Biaya } \text { Tunai }} \\
& \mathrm{R} / \mathrm{C} \text { atas biaya total }=\frac{\text { Total Penerimaan }}{\text { Total Biaya }}
\end{aligned}
$$

$\mathrm{R} / \mathrm{C}>1$, artinya usahatani tumpangsari menguntungkan dan layak dilaksanakan.

$\mathrm{R} / \mathrm{C}<1$, artinya kegiatan usahatani tumpangsari tidak menguntungkan dan tidak layak dilaksanakan.

$\mathrm{R} / \mathrm{C}=1$, artinya kegiatan usahatani tumpangsari berada pada kondisi tidak untung dan tidak rugi (Soekartawi, 2006). 


\section{HASIL DAN PEMBAHASAN}

1. Analisis Fungsi Produksi

Analisis fungsi produksi diuji secara statistik dengan menggunakan uji koefisien determinasi $\left(\mathrm{R}^{2}\right)$, uji $\mathrm{F}$, dan uji t pada tingkat kepercayaan 95\%. Berikut uraian mengenai uji statistika :

Tabel 1. Hasil Uji Koefisien Determinasi $\left(\mathrm{R}^{2}\right)$

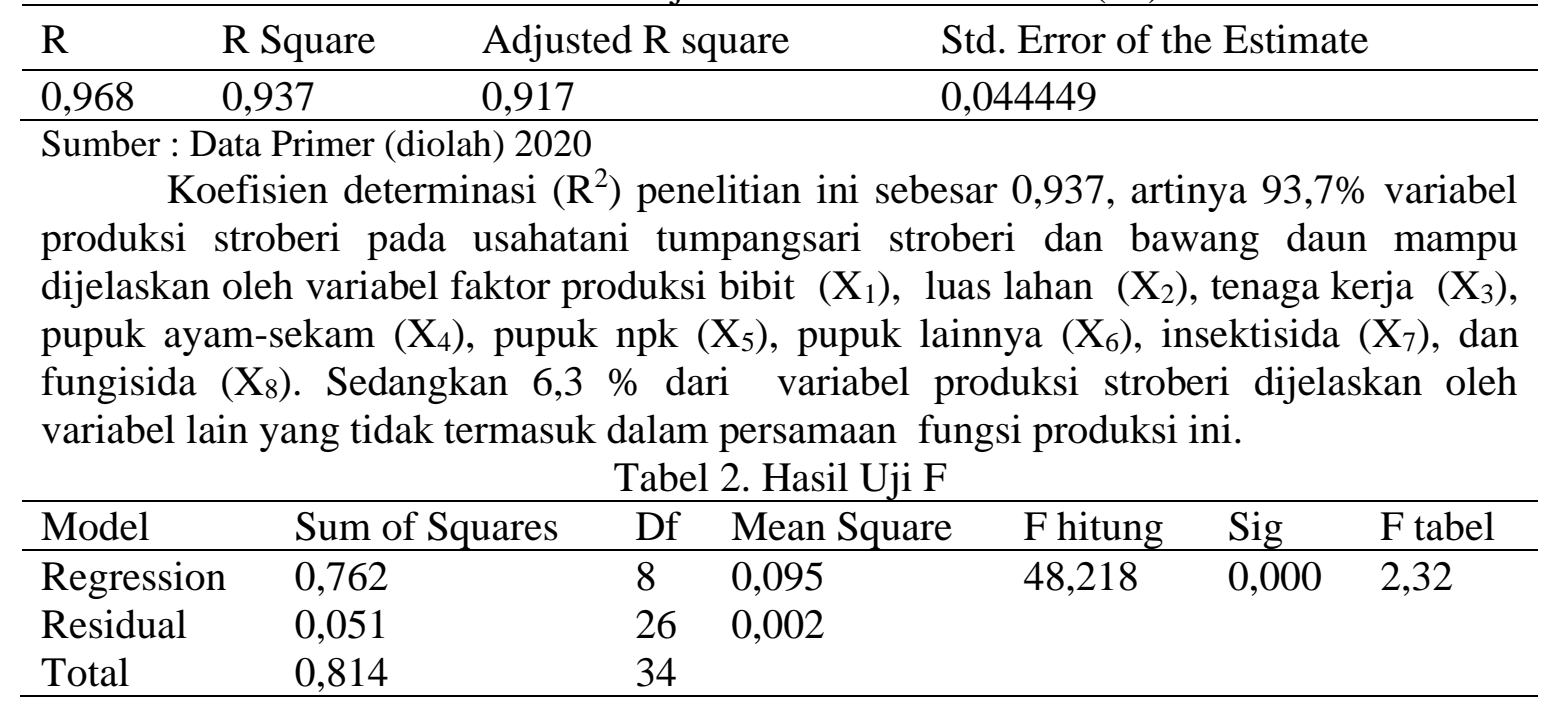

Sumber : Data Primer (diolah) 2020

F hitung $(48,218)$ lebih besar daripada $F$ tabel $\alpha=0,05(2,32)$ sehingga dapat dikatakan bahwa faktor produksi (bibit, luas lahan, tenaga kerja, pupuk ayam-sekam, pupuk NPK, pupuk lain, insektisida, dan fungisida) secara bersama- sama berpengaruh nyata terhadap produksi usahatani tumpangsari stroberi dengan bawang daun yang dihasilkan pada tingkat kepercayaan $95 \%$.

Tabel 3. Hasil Estimasi Fungsi Produksi Stroberi-bawang daun

\begin{tabular}{lrrrr}
\hline Model & Notasi & Koef & t hit & Sig. \\
\hline Konstanta & & 0,36 & 0,87 & 0,389 \\
Bibit Tumpangsari Stroberi-Bawang Daun & $X_{1}$ & 0,46 & 6,02 & $0,000^{*}$ \\
Luas Lahan Usahatani Tumpangsari Stroberi- & $X_{2}$ & $-0,14$ & $-2,08$ & $0,047^{*}$ \\
Bawang Daun & & & & \\
Tenaga Kerja & $X_{3}$ & 0,65 & 2,80 & $0,009^{*}$ \\
Pupuk Ayam-Sekam & $X_{4}$ & $-0,08$ & $-1,12$ & 0,270 \\
Pupuk NPK-Phonsska & $X_{5}$ & 0,03 & 0,72 & 0,477 \\
Pupuk lain & $X_{6}$ & 0,01 & 0,55 & 0,587 \\
Insektisida & $X_{7}$ & 0,03 & 2,15 & $0,041^{*}$ \\
Fungisida & $X_{8}$ & 0,01 & 0,37 & 0,710 \\
\hline
\end{tabular}

Sumber : Data Primer (diolah) 2020

Keterangan : * Signifikan pada taraf 5\%

Variabel faktor produksi yang berpengaruh signifikan secara parsial terhadap produksi stroberi-bawang daun adalah bibit, luas lahan, tenaga kerja, dan insektisida. Variabel pupuk ayam-sekam, pupuk NPK-Phonska, pupuk lainnya, dan fungisida secara parsial tidak berpengaruh terhadap produksi stroberi. Hasil analisis menunjukkan faktor produksi luas lahan berpengaruh negatif terhadap produksi usahatani tumpangsari stroberi dengan bawang daun, di mana tiap penambahan satu satuan luas lahan akan mengurangi produksinya. Adanya penambahan luas lahan garapan akan menambah sarana produksi lainnya. Penambahan luas lahan pada usahatani tumpangsari stroberi 
dengan bawang daun sulit dilakukan karena beberapa faktor yakni ketersediaan bibit dengan mutu baik yang langka, perawatan stroberi yang rumit, tenaga kerja yang terbatas, dan permasalahan permodalan. Perawatan stroberi harus dilakukan secara rutin dan telaten. Menambah luas lahan akan berdampak pada perawatan yang tidak maksimal karena curahan tenaga kerja yang kurang. Selain itu semakin luas lahan garapan petani maka semakin besar modal yang harus dikeluarkan dan semakin tinggi pula resiko yang harus ditanggung oleh petani.

\section{Analisis Efisiensi Harga}

Usahatani dapat dikatakan efisien jika dalam proses produksi tersebut terdapat perbandingan NPM dan BKM sama dengan satu untuk semua faktor produksi yang digunakan.

Tabel 4. Perhitungan Nilai Produk Marjinal

\begin{tabular}{|c|c|c|c|c|}
\hline Uraian & $\begin{array}{l}\text { Bibit tumpangsari } \\
\text { stroberi- bawang } \\
\text { daun (pohon) }\end{array}$ & $\begin{array}{l}\text { Luas Lahan } \\
\qquad(\mathrm{m} 2)\end{array}$ & $\begin{array}{c}\text { Tenaga Kerja } \\
\text { (HKSP) }\end{array}$ & $\begin{array}{l}\text { Insektisida } \\
\quad(\mathrm{ml})\end{array}$ \\
\hline $\mathrm{Py}$ & 26.176 & 26.176 & 26.176 & 26.176 \\
\hline Y rata-rata & 572,45 & 572,45 & 572,45 & 572,45 \\
\hline Koefisien Input & 0,461 & $-0,146$ & 0,654 & 0,037 \\
\hline $\begin{array}{l}\text { Penggunaan input rata- } \\
\text { rata }\end{array}$ & 6749 & 1107 & 62,82 & 493,84 \\
\hline Rumus NPM & $\left(\beta \mathrm{i}^{*} \mathrm{Y}^{*} \mathrm{Py}\right) / \mathrm{Xi}$ & $\begin{array}{l}\left(\beta \mathrm{i}^{*} \mathrm{Y} * \mathrm{Py}\right) / \mathrm{X} \\
\mathrm{i}\end{array}$ & $\begin{array}{l}\left(\beta i^{*} Y^{*} \mathrm{Py}\right) / \mathrm{X} \\
\mathrm{i}\end{array}$ & $\begin{array}{l}\left(\beta \mathrm{i}^{*} \mathrm{Y}^{*} \mathrm{Py}\right) / \mathrm{X} \\
\mathrm{i}\end{array}$ \\
\hline Nilai NPM Input & 1023,61 & $-1976,29$ & 155990,34 & $\mathbf{1 1 2 2 , 7 0}$ \\
\hline \multicolumn{5}{|c|}{ Tabel 5. Hasil Pendugaan Efisiensi Harga } \\
\hline \multicolumn{2}{|l|}{ Faktor Produksi (satuan) } & NPM & BKM & NPM/BKM \\
\hline \multicolumn{2}{|c|}{ Bibit tumpangsari stroberi- bawang daun (pohon) } & 1023,61 & 1.000 & 1,02 \\
\hline \multicolumn{2}{|c|}{ Luas Lahan $\left(\mathrm{m}^{2}\right)$} & $-1976,03$ & 9.218 & $-0,21$ \\
\hline \multicolumn{2}{|l|}{ Tenaga Kerja (HKSP) } & 155990,3 & 71.123 & 2,19 \\
\hline \multicolumn{2}{|l|}{ Insektisida (ml) } & 1122,70 & 124 & 9,05 \\
\hline
\end{tabular}

Sumber : Data Primer (diolah) 2020

Faktor produksi bibit memiliki nilai NPM sebesar 1023,61 artinya penambahan 1 pohon bibit akan meningkatkan peneriamaan sebesar Rp1.023,61 dengan biaya tambahan yang dikeluarkan sebesar Rp1000,00 input tenaga kerja memiliki nilai NPM sebesar 155.990,00 artinya penambahan jumlah 1 tenaga kerja meningkatkan penerimaan sebesar Rp155.990,00 dengan biaya tambahan yang dikeluarkan sebesar Rp71.123,00. Insektisida memiliki nilai NPM sebesar 1122,70 artinya setiap penambahan 1 mililiter insektisida cair akan meningkatkan penerimaan sebesar Rp1122,70 dengan biaya tambahan yang dikeluarkan sebesar Rp124,00. Nilai NPM/BKM untuk faktor produksi luas lahan kurang dari satu yang artinya penambahan luas lahan menyebabkan tambahan pengeluaran yang lebih besar daripada tambahan penerimaan yang akan diperoleh sehingga harus dikurangi. Nilai NPM [-1976,03], artinya penambahan luas lahan 1m2 akan meningkatkan pendapatan sebesar Rp1.976,03 dengan biaya tambahan yang dikeluarkan sebesar Rp9.218,00 dimana peningkatan penerimaan yang didapat lebih kecil daripada biaya yang dikeluarkan. Perhitungan efisiensi harga faktor produksi luas lahan menunjukkan bahwa luas lahan sudah tidak efisien, karena penambahan luas lahan akan menyebabkan tambahan pendapatan yang diperoleh lebih kecil daripada tambahan biaya yang dikeluarkan Efisiensi pada suatu lahan pertanian dapat dicapai apabila usahatani dijalankan dengan tertib dalam 
mengelola faktor produksi dengan adanya teknologi yang tepat (Daniel, 2004) (Raisha and Soliha, 2019).

Perhitungan efisiensi harga faktor produksi bibit menunjukkan bahwa penggunaan bibit belum efisien, penambahan bibit akan memberikan tambahan penerimaan yang lebih besar. Petani masih dapat meningkatkan penggunaan bibit pada usahatani tumpangsari stroberi dengan bawang daun. Bibit stroberi yang dianjurkan yakni 40.000-83.333 per hektarnya atau 4000-8333 per $1000 \mathrm{~m}^{2}$ (Rukmana, 2012). Jumlah bibit yang digunakan dalam usahatani tumpangsari stroberi dengan bawang daun yakni 5.755 per $1000 \mathrm{~m}^{2}$. Penambahan bibit stroberi masih dapat dilakukan dengan mempersempit jarak tanamnya (Wiyanti, 2020). Penambahan bibit juga diimbangi dengan kualitas mutunya. Ketersediaan bibit stroberi dengan mutu yang baik di Desa Serang sudah langka. Bibit stroberi di Desa Serang didapat melalui pemisahan rumpun tanaman induk padahal pembibitan dengan cara tersebut mempunyai produktivitas tidak setinggi tanaman induknya, sehingga bibit yang diperoleh dari pemisahan rumpun tanaman induk yang berulang-ulang, produktivitasnya akan semakin menurun serta rentan terhadap penyakit (Soemadi, 1997). Peningkatan penggunaan bibit harus diimbangi dengan kualitas mutu bibit yang baik.

Perhiungan efisiensi harga menunjukkan bahwa faktor produksi tenaga kerja belum efisien. Tenaga kerja masih dapat ditambahkan karena tambahan hasil produksi yang diperoleh secara ekonomi akan lebih besar daripada tambahan biaya tenaga kerja yang dikeluarkan. Jumlah produktivitas dapat meningkat dengan adanya penambahan tenaga kerja (Febriandi, Hadi and Yusri, 2017). Penambahan tenaga kerja ini hendaknya bukan hanya dari segi kuantitas saja, tetapu juga peningkatan kualitas sumber daya manusia, melalui penyuluhan dan pelatihan. Penyuluhan berperan penting dalam meningkatkan produktivitas usahatani stroberi (Vintarno, Sugandi and Adiwisastra, 2019). Keahlian petani dalam mengelola pengunaan faktor produksi merupakan hal yang penting. Pemanfaatan faktor produksi yang tepat, dapat menekan biaya produksi serta meningkatkan produksi dari usahatani tersebut (Daniel, 2004). Oleh sebab itu para petani harus diberikan penyuluhan dalam menggunakan dan memanfaatkan faktorfaktor produksi dalam usahataninya.

Perhitungan efisiensi harga menunjukkan bahwa input insektisida belum efisien. Petani membatasi penggunaan insektisida pada usahatani tumpangsari stroberi dengan bawang daun. Penyemprotan insektisida dilakukan untuk mencegah terjadinya serangan hama sebelum pembungaan berlangsung. Mengingat penggunaan insektisida yang berlebih akan berbahaya. Penambahan penggunaan obat-obatan pada usahatani perlu diimbangi dengan pengetahuan petani mengenai bahayanya insektisida. Pemanenan buah stroberi dilakukan pada interval waktu yang singkat dan menyebabkan insektisida belum terurai secara maksimal dan ditakutkan masih meninggalkan residu pada kulit buah stroberi. Buah stroberi memiliki lapisan kulit yang tipis dan mudah terluka sehingga proses pencucian membuat buah cepat membusuk (Rukmana, 2012). 
Tabel 6. Struktur Biaya Rata Rata yang Dikeluarkan

\begin{tabular}{|c|c|c|c|c|c|}
\hline No & Uraian & Satuan & Biaya Per Ut & $\begin{array}{c}\text { Biaya Per } \\
1000 \mathrm{~m}^{2} \\
\end{array}$ & Persentase (\%) \\
\hline \multirow[t]{23}{*}{1} & BIAYA TUNAI & & & & \\
\hline & A Biaya Tetap & & & & \\
\hline & 1. Pajak Tanah & $\mathrm{Rp}$ & 10.206 & 9.218 & 0,07 \\
\hline & 2. Penyusutan alat & $\mathrm{Rp}$ & 199.886 & 180.542 & 1,46 \\
\hline & 3. Pembuatan kolam & $\mathrm{Rp}$ & 24.771 & 22.374 & 0,18 \\
\hline & Sub total & & 234.863 & 212.134 & 1,71 \\
\hline & B Biaya Variabel : & & & & \\
\hline & 1. Penggunaan TKLK & $\mathrm{Rp}$ & 733.893 & 662.871 & 5,34 \\
\hline & 2. Pupuk Ayam-Sekam & $\mathrm{Rp}$ & 701.000 & 633.161 & 5,1 \\
\hline & 3. Pupuk NPK & $\mathrm{Rp}$ & 144.943 & 130.916 & 1,06 \\
\hline & 4. Pupuk Lainnya & & & & \\
\hline & a) Pupuk Dasar & $\mathrm{Rp}$ & 185.814 & 167.832 & 1,35 \\
\hline & b) Pupuk Kocor & $\mathrm{Rp}$ & 749.566 & 677.027 & 5,46 \\
\hline & c) Pupuk Semprot & $\mathrm{Rp}$ & 304.053 & 274.629 & 2,21 \\
\hline & 5. Insektisida & & & & \\
\hline & a) Insektisida Padat & $\mathrm{Rp}$ & 28.160 & 25.435 & 0,21 \\
\hline & b) Insektisida Cair & $\mathrm{Rp}$ & 33.007 & 29.813 & 0,24 \\
\hline & 6. Fungisida & & & & \\
\hline & a) Fungisida Padat & $\mathrm{Rp}$ & 85.798 & 77.495 & 0,62 \\
\hline & b) Fungisida Cair & $\mathrm{Rp}$ & 32.790 & 29.617 & 0,24 \\
\hline & 7. Biaya Dolomit & $\mathrm{Rp}$ & 16.843 & 15.213 & 0,12 \\
\hline & Sub total & & 3.015 .866 & 2.724 .008 & 21,96 \\
\hline & Total Biaya Tunai & & 3.250 .729 & 2.936 .142 & 23,67 \\
\hline \multirow[t]{9}{*}{2} & BIAYA NON TUNAI & & & & \\
\hline & A. Biaya Tetap : & & & & \\
\hline & 1. Penggunaan TKDK & $\mathrm{Rp}$ & 3.734 .929 & 3.373 .484 & 27,19 \\
\hline & Sub total & & 3.734 .929 & 3.373 .484 & 27,19 \\
\hline & $\begin{array}{l}\text { B. Biaya Variabel: } \\
\text { 1. Bibit }\end{array}$ & & & & \\
\hline & a) Bibit Stroberi & $\mathrm{Rp}$ & 6.371 .429 & 5.754 .839 & 46,39 \\
\hline & b) Bibit Bawang Daun & $\mathrm{Rp}$ & 377.143 & 340.645 & 2,75 \\
\hline & Sub total & & 6.748 .571 & 6.095 .484 & 49,14 \\
\hline & Total Biaya Non-Tunai & & 10.483 .500 & 9.468 .968 & 76,33 \\
\hline 3 & Total Biaya & & 13.734 .229 & 12.405 .110 & 100 \\
\hline
\end{tabular}

Sumber : Data Primer (diolah) 2020

Berdasarkan Tabel 6 total biaya per usahatani yang dikeluarkan petani tumpangsari stroberi dengan bawang daun yakni Rp13.734.229,00 terdiri dari biaya tunai sebesar Rp3.250.729,00 dan biaya non tunai sebesar Rp10.483.500,00. Sementara total biaya per $1000 \mathrm{~m}^{2}$ yang dikeluarkan petani tumpangsari stroberi dengan bawang daun yakni Rp12.405.110,00 terdiri dari biaya tunai sebesar Rp2.936.142,00 dan biaya non tunai Rp9.468.968,00. Biaya tunai mempunyai persentase sebesar 23,67\% dan biaya non tunai sebesar $76,33 \%$. 
Tabel 7. Penerimaan Rata Rata Usahatani Tumpangsari Stroberi-Bawang Daun

\begin{tabular}{|c|c|c|c|c|c|c|}
\hline Uraian & $\begin{array}{c}\text { Produksi } \\
\text { Rata } \\
\text { Rata Per } \\
\text { Ut } \\
1107 \mathrm{~m}^{2} \\
(\mathrm{Kg})\end{array}$ & $\begin{array}{c}\text { Produksi } \\
\text { Rata Rata } \\
\text { Per } \\
1000 \mathrm{~m}^{2} \\
(\mathrm{Kg})\end{array}$ & Harga $(\mathrm{Rp} / \mathrm{Kg})$ & $\begin{array}{l}\text { Penerimaan } \\
\text { Per Ut (Rp) }\end{array}$ & $\begin{array}{c}\text { Penerimaan } \\
\text { Per } 1000 \mathrm{~m}^{2} \\
\quad(\mathrm{Rp})\end{array}$ & $\begin{array}{c}\text { Persentase } \\
\left.(\%)^{*}\right)\end{array}$ \\
\hline \multirow{3}{*}{$\begin{array}{l}\text { Stroberi } \\
\text { Bawang } \\
\text { Daun }\end{array}$} & 468,31 & 422,99 & 26.176 & 12.258 .593 & 11.072 .277 & 81,81 \\
\hline & 681,00 & 615,48 & 4.000 & 2.725 .714 & 2.461 .935 & 18,19 \\
\hline & & Total & & 14.984 .307 & 13.534 .213 & 100,00 \\
\hline
\end{tabular}

Sumber : Data Primer (diolah) 2020

Keterangan : *) Perbandingan Antara Penerimaan Per 1000m² dengan Penerimaa Per Ut (1107)

Penerimaan usahatani tumpangsari stroberi dengan bawang daun yakni Rp14.984.307 per usahatani dan Rp13.534.213 per $1000 \mathrm{~m}^{2}$. Jumlah produksi stroberi petani responden rata rata 468,31 $\mathrm{kg}$ per usahatani dan 422,99 $\mathrm{kg}$ per $1000 \mathrm{~m}^{2}$ dengan harga jual rata rata Rp26.176,00 per kilogramnya. Sehingga penerimaan stroberi rata yang didapat secara berturut turut yakni Rp12.258.593,00 per usahatani dan Rp11.072.277,00 per $1000 \mathrm{~m}^{2}$ dengan persentase sebesar $81,81 \%$ dari total penerimaan. Jumlah produksi bawang daun petani responden rata rata yakni $681 \mathrm{~kg}$ per usahatani dan 615,48 per $1000 \mathrm{~m} 2$ dengan harga jual Rp4.000 per kilogramnya. Sehingga penerimaan rata rata bawang daun yang didapat petani secara berturut turut yakni sebesar Rp2.725.714 per usahatani dan Rp2.461.935 per $1000 \mathrm{~m}^{2}$ dengan persentase sebesar $18,19 \%$ dari total penerimaan.

Tabel 78. Pendapatan Rata Rata Usahatani

\begin{tabular}{llrr}
\hline No. & Uraian & Per Ut & Per 1000m2 \\
\hline 1. & Pendapatan Atas Biaya Tunai & 11.733 .578 & 10.598 .071 \\
2. & Pendapatan Atas Biaya Total & 1.250 .078 & 1.129 .103 \\
\hline
\end{tabular}

Sumber : Data Primer (diolah) 2020

Pendapatan atas biaya tunai pada usahatani tumpangsari stroberi dengan bawang daun per usahatani adalah sebesar Rp11.733.578,00. Pendapatan atas biaya total pada usahatani tumpangsari stroberi dengan bawang daun per usahatani adalah sebesar Rp1.250.078,00.

Tabel 9. Kelayakan Usahatani Timpangsari Stroberi

\begin{tabular}{llc}
\hline No. & Uraian & Nilai \\
\hline 1. & R/C Atas Biaya Tunai & 4,61 \\
2. & R/C Atas Biaya Total & 1,09 \\
\hline \multicolumn{2}{l}{ Sumber $:$ Data Primer (diolah) 2020 }
\end{tabular}

$\mathrm{R} / \mathrm{C}$ atas biaya tunai adalah sebesar 4,61 , artinya setiap satu rupiah biaya tunai yang dikeluarkan atas usahatani tumpansari stroberi dan bawang daun akan menghasilkan penerimaan sebesar Rp4,61. R/C atas biaya total adalah 1,09, artinya setiap satu rupiah biaya total yang dikeluarkan untuk usahatani tumpangsari wortel akan menghasilkan penerimaan sebesar Rp1,09. Nilai R/C baik atas biaya tunai maupun biaya total memiliki nilai lebih besar daripada satu, sehingga usahatani tumpangsari stroberi dan bawang daun di Desa Serang dapat dikatakan layak untuk terus dijalankan oleh petani. 


\section{KESIMPULAN}

Penggunaan faktor produksi bibit, luas lahan, tenaga kerja, dan insektisida secara parsial berpengaruh terhadap produksi tumpangsari stroberi, sedangkan faktor produksi pupuk ayam-sekam, pupuk NPK-Phonska, pupuk lainnya dan fungisida tidak berpengaruh terhadap produksi tumpangsari stroberi. Faktor produksi bibit, tenaga kerja, dan insektisida belum efisien. Faktor produksi luas lahan sudah tidak efisien. Usahatani tumpangsari stroberi dan bawang daun di Desa Serang berdasarkan R/C rasio atas biaya tunai dan $\mathrm{R} / \mathrm{C}$ rasio atas biaya total dapat dikatakan menguntungkan layak untuk terus dijalankan oleh petani. Guna meningkatkan produksi tumpangsari stroberi, maka diperlukan intensifikasi dan ekstensifikasi usahatani.

\section{DAFTAR PUSTAKA}

Daniel, M. (2004) Pengantar Ekonomi Pertanian. Jakarta: PT Bumi Aksara.

Febriandi, R., Hadi, S. and Yusri, J. (2017) 'Pengaruh Tenaga Kerja Dan Tingkat Optimasi Penggunaan Tenaga Kerja Pada Usahatani Nenas Lahan Skala Sempit Dan Skala Luas Di Kabupaten Kampar', Jurnal JOM Faperta UR, 4(1), pp. 111.

Raisha, R. F. and Soliha, E. H. (2019) 'Analisis Efisiensi Teknis Alokatif Dan Ekonomi Usahatani Semangka Di Desa Mojosari Kecamatan Puger Kabupaten Jember', JSEP : Jurnal Sosial Ekonomi Pertanian, 12(3), pp. 22-33.

Rukmana, R. (2012) Stroberi Budidaya dan Pascapanen. Yogyakarta: Penerbit Kanisius.

Soekartawi (2003) Teori Ekonomi Produksi dengan Pokok Bahasan Analisis Fungsi Produksi Cobb-Douglas. Jakarta: Raja Grafindo Persada.

Soekartawi (2006) Analisis Usaha Tani. Jakarta: UI-Press.

Soemadi, W. (1997) Stroberi Di Pot dan Kebun. Yogyakarta: Aneka.

Suwandi, R., Rosliani, N. and Setiawati, W. (2003) 'Interaksi Tanaman Pada Sistem Tumpangsari Tomat Dan Cabai Di Dataran Tinggi', Jurnal Hortikultura, 13(4), pp. 244-250.

Vintarno, J., Sugandi, Y. S. and Adiwisastra, J. (2019) 'Perkembangan Penyuluhan Pertanian Dalam Mendukung Pertumbuhan Pertanian Di Indonesia', Responsive: Jurnal Pemikiran Dan Penelitian Administrasi, Sosial, Humaniora Dan Kebijakan Publik, 1(3), pp. 90-96.

Wijayanti, I. K. E. (2020) 'Stochastic Frontier Analysis on Technical Efficiency of Strawberry Farming in Purbalingga Regency Indonesia', Jurnal Teknosains, 9(2), pp. 105-115. 